Int. J. Electrochem. Sci., 13 (2018) $6503-6521$

\title{
Preparation of Semiconductor Zinc Oxide Nanoparticles as a Photocatalyst to Get Rid of Organic Dyes Existing Factories in Exchange for Reuse in Suitable Purpose
}

\author{
A. Alhadhrami ${ }^{1}$, Abdulraheem S.A. Almalki ${ }^{1}$, Abdel Majid A. Adam ${ }^{1}$, and Moamen S. Refat ${ }^{1,2}$ \\ ${ }^{1}$ Department of Chemistry, Faculty of Science, Taif University, Al-Hawiah, Taif, P.O. Box 888 Zip \\ Code 21974, Saudi Arabia \\ ${ }^{2}$ Department of Chemistry, Faculty of Science, Port Said University, Port Said, Egypt \\ "E-mail: msrefat@yahoo.com
}

doi: $10.20964 / 2018.07 .04$

Received: 11 March 2018 / Accepted: 19 April 2018 / Published: 5 June 2018

\begin{abstract}
A new photocatalyst zinc(II) oxide ( $\mathrm{ZnO})$ was synthesized using a microwave-assisted green method using $p$-hydroxybenzoic acid and zinc nitrate as precursors. The sample was characterized by FTIR, UV-visible, EDX, XRD, SEM and TEM techniques. The molecular formula of the primary precursor $\left[\mathrm{Zn}_{2}\left(\mathrm{C}_{7} \mathrm{H}_{5} \mathrm{O}_{3}\right)_{2}\left(\mathrm{NO}_{3}\right)_{2}\left(\mathrm{H}_{2} \mathrm{O}\right)_{4}\right]$ binuclear zinc(II) complex was discussed using elemental analyses (CHN), FTIR, UV-visible, XRD, SEM and thermal analysis (TG). This new binuclear complex was formed with $p$-hydroxybenzoic acid as a bridged chelate connecting two zinc metal ions through the carboxylate groups. The chelation assignments declare that $\mathrm{Zn}(\mathrm{II})$ metals are coordinated to the $p$ hydroxybenzoate ligand with octahedral geometry. The photocatalytic property of the $\mathrm{ZnO}$ products was examined for the degradation of methyl red (MR), methyl orange (MO) and methylene blue (MB) solutions. The resulting data demonstrated a photocatalytic efficiency towards the removal of the selected organic dyes. The Electrical properties of ZnO NPs were measured within the temperature range $313-403 \mathrm{~K}$.
\end{abstract}

Keywords: ZnO; precursors; organic dyes; XRD; TEM; photocatalyst; electrical properties.

\section{$\underline{\text { FULL TEXT }}$}

(C) 2018 The Authors. Published by ESG (www.electrochemsci.org). This article is an open access article distributed under the terms and conditions of the Creative Commons Attribution license (http://creativecommons.org/licenses/by/4.0/). 